\title{
REPRESENTACIONES SOCIALES ACERCA DE LA DONACIÓN DE ÓRGANOS EN ENFERMEROS DE UNA UNIDAD DE PACIENTE CRÍTICO
}

\author{
SOCIAL REPRESENTATIONS BY NURSES WORKING AT A CRITICAL PATIENT \\ UNIT CARE ABOUT ORGAN DONATIONS \\ REPRESENTAÇÕES SOCIAIS DOS PROFISSIONAIS DE ENFERMAGEM \\ DA UNIDADE DO PACIENTE CRÍTICO ADULTO EM RELAÇÃO À DOAÇÃO DE ÓRGÃOS
}

Mirliana Ramírez Pereira

Universidad de Chile. Santiago, Chile.

mirliana@uchile.cl

ORCID: 0000-0003-1439-4162

Constanza Rojas Vásquez

Hospital de Coquimbo. Coquimbo, Chile.

ORCID: 0000-0002-0749-9356

Cecilia Beltrán Martiz

Universidad Católica del Norte. Coquimbo, Chile.

ORCID: 0000-0002-1759-279X

Rubén Polanco Huerta

Universidad Católica del Norte. Coquimbo, Chile.

DOI: http://dx.doi.org/10.22235/ech.v5i2.1285

Recibido: 19/10/2016

Aceptado: 15/11/2016

\section{RESUMEN}

Chile posee una de las tasas más bajas de donación de órganos a nivel mundial, llegando a siete donantes efectivos por millón de habitantes. El objetivo de esta investigación es conocer las representaciones sociales de los enfermeros en una unidad de cuidados críticos en relación a la donación de órganos. Se trata de un estudio de tipo cualitativo y se utilizó Teoría Fundada como enfoque teórico - metodológico. Se realizaron entrevistas en profundidad, que luego fueron transcritas y codificadas. En el análisis de las entrevistas se formaron códigos, luego se agruparon según semánticas por categorías, y se reagruparon para formar las familias o supra categorías correspondientes. En base a los discursos emergieron once categorías. Posteriormente se llegó a la formación de tres familias: sentimientos sobre la donación de órganos, conociendo la donación de órganos y gestión del proceso de donación de órganos. Se pudo determinar que el proceso de donación de órganos es complejo, presentando diversas causas expresadas por los profesionales, las que aparentemente en ocasiones condicionan una respuesta por parte de los familiares del donante. Las experiencias de los enfermeros generan sentimientos de diversa índole con respecto a la donación de órganos; sin embargo, reconocen su importancia, visualizándola como una posibilidad de sobrevida.

Palabras clave: Investigación en Enfermería, Obtención de Tejidos y Órganos, Enfermeros, Investigación cualitativa, Cuidados Críticos.

\section{ABSTRACT}

Chile has one of the lowest organ donation rates in the world, seven donors per million. The aim of this research is to understand the social representations of nurses working in a critical care unit in relation to organ donation. This research is a qualitative study with a Grounded Theory perspective. Data from interviews with professional nurses was collected, transcribed and coded. Data was then grouped into eleven categories in three main families: the feelings about organ donation, organ donation knowledge and the management of the process of organ donation. It was determined that the organ procurement process is complex due to various reasons expressed by the professionals interviewed, which sometimes condition the response given by the donor's relatives. Nurses has different feelings about organ donation; however, they recognize its importance, viewing it as a chance of survival.

Keywords: Nursing Research, Tissue and Organ Procurement, Nurses, Qualitative Research, Critical Care.

\section{RESUMO}

Chile tem uma das mais baixas taxas de doação de órgãos no mundo, atingindo 7 doadores efetivos por milhão de habitantes. O objetivo desta pesquisa é compreender as representações sociais de enfermeiros em unidade de cuidados intensivos em relação à doação de órgãos. Esta pesquisa corresponde 
a um estudo qualitativo e Teoria foi usada Fundado como abordagem teórico - metodológica. entrevistas, que foram então transcritas codificado realizada. Na análise de entrevistas com códigos aspectos importantes foram formados, em seguida, eles foram agrupados de acordo com as categorias semânticas, e reagrupadas para formar famílias ou acima categorias correspondentes. Com base nos discursos emergiram onze categorias. Posteriormente, ele deu à formação de 3 famílias: sentimentos de doação de órgãos, doação de órgão conhecer e gestão de processos de doação de órgãos. Em conclusão, foi determinado que o processo de captação de órgãos é complexo, apresentando várias razões expressas por profissionais que, aparentemente, por vezes, determinam uma resposta por parentes do doador. As experiências de enfermeiros gerar sentimentos de vários tipos sobre a doação de órgãos, no entanto, eles reconhecem a sua importância, vendo-a como uma chance de sobrevivência.

Palavras-chave: Pesquisa em Enfermagem, Obtenção de Tecidos e Órgãos, Enfermeiras e Enfermeiros Pesquisa Qualitativa, Cuidados Críticos.

\section{INTRODUCCIÓN}

El Consejo Internacional de Enfermeras (CIE, por su sigla en español) explica la Enfermería como aquella disciplina que "abarca los cuidados, autónomos y en colaboración, que se prestan a las personas de todas las edades, familias, grupos y comunidades, enfermos o sanos, en todos los contextos, e incluye la promoción de la salud, la prevención de la enfermedad y los cuidados de los enfermos, discapacitados, y personas moribundas. Funciones esenciales de la enfermería son la defensa, el fomento de un entorno seguro, la investigación, la participación en la política de salud, en la gestión de los pacientes y los sistemas de salud, y la formación" (1).

De la conceptualización expuesta en el párrafo anterior se puede desprender que el cuidado corresponde al eje central de la Enfermería, otorgado por la enfermera en todo el ciclo vital de la persona. En este contexto, un área donde la disciplina adquiere un rol relevante es en relación con la donación de órganos, proceso en el cual Enfermería participa en el cuidado del donante en las unidades críticas, de la familia del donante y como parte de los equipos de procuramiento.

La donación de órganos se define como "el procedimiento médico mediante el cual se extraen tejidos de un cuerpo humano y se reimplantan en otro, con el propósito de que el tejido trasplantado realice en su nueva localización la misma función que realizaba previamente" (2). Chile posee una muy baja tasa de donación en relación con otros países; en 2015 fue sólo 7 donantes por millón de habitantes. Esto es a pesar de la promulgación de la Ley 20413 del año 2010, según la cual, todas las personas mayores de 18 años automáticamente se convierten en donantes universales a menos que se exprese lo contrario ante un registro notarial. Con esto se esperaba que aumentara las tasas de donación; sin embargo, ese mismo año Chile presentó la tasa más baja de donación en la historia del país con 5,4 donantes por millón de habitantes (3).
El proceso de donación de órganos se encuentra bajo la supervisión de la Coordinación Nacional de Procuramiento y Trasplantes de órganos y tejidos, el organismo técnico encargado de velar para que los programas de donación y trasplante funcionen correctamente en la red pública y la privada. Este departamento depende directamente de la Subsecretaría de redes asistenciales del Ministerio de Salud, y fue creado por la ley $\mathrm{N}^{\circ}$ 20.413, en enero de 2010, con la misión de implementar una política nacional en el marco de las normas, objetivos y principios establecidos en la normativa vigente (4). Las etapas del proceso de Procuramiento y Donación de Órganos son: detección y evaluación de los potenciales donantes, mantenimiento del potencial donante, certificación de muerte encefálica, solicitud de testimonio de última voluntad, extracción y trasplante o almacenaje (5).

La etapa de Detección y evaluación de potenciales donantes es la primera de este proceso y comienza con la detección de los posibles donantes, es decir, personas que presenten Glasgow igual o menor a 7, daño neurológico severo, que se encuentre fuera de alcance neuroquirúrgico y con soporte ventilatorio y hemodinámico. Por eso es importante que el profesional a cargo de la coordinación local de procuramiento sea notificado con la información de estos posibles donantes, además de la pesquisa diaria, en Unidad de Cuidados Intensivos (UCI) y Servicios de Urgencia (SU), que efectúa la coordinación local de procuramiento de posibles donantes como también la valoración de los criterios absolutos de exclusión $(\mathrm{VIH}$, hepatitis $\mathrm{B}$ y C, tumor maligno con capacidad de metastizar, sepsis o infección aguda potencialmente transmisible). Una vez pesquisados estos posibles donantes se ingresarán al programa de seguimiento en el Sistema de integración de donación y trasplantes (SIDOT) (5).

La segunda etapa es la Mantención del potencial donante. Todos los posibles y potenciales donantes deben ser manejados en Unidades de Paciente Crítico (UPC), por lo que estas unidades deben de proveer todas las condiciones para un manejo óptimo del paciente. Independiente de la decisión posterior de ser o no donante, todos los potenciales donantes deben mantenerse bajo condiciones clínicas óptimas, las cuales son: ventilación mecánica invasiva, monitorización electrocardiográfica continua, presión arterial invasiva, oximetría de pulso, medición horaria de diuresis, apoyo con drogas vasoactivas y personal entrenado para el cuidado de pacientes críticos. Se mantiene el soporte de los órganos hasta la extracción, siempre y cuando la familia haya accedido a donarlos. En caso contrario, el cese del mantenimiento ocurre en caso de manifestación expresa de la familia de retirar el soporte, negativa familiar de la donación de órganos, descarte del paciente como potencial donante desde la coordinación local o nacional de procuramiento (5).

La etapa siguiente es la de Certificación de Muerte Encefálica; todos los pacientes con Glasgow 3 y daño neurológico severo e irreversible deben ser sometidos a la certificación de Muerte Encefálica y cumplir con ciertos prerrequisitos clínicos. Además debe ser certificada por al menos dos médicos, siendo uno de ellos con especialidad en neurología o neurocirugía. La fecha y hora de la certificación de la muerte encefálica del paciente 
corresponde a la data de defunción del paciente y ésta debe ser notificada a los familiares por el equipo tratante (5).

La cuarta etapa corresponde a la Solicitud de testimonio de última voluntad (STUV). En esta etapa se le comunica a la familia del paciente de la potencialidad de donación de los órganos, con el fin de validar la última voluntad expresa por el paciente en vida. Para que esta etapa sea llevada a cabo se requieren ciertos requisitos previos, tales como certificación de muerte encefálica, notificación a la familia de fallecimiento y criterios de exclusión descartados y evaluados por la coordinación local de procuramiento (5).

La última etapa es la Extracción y trasplante; aquí se extraen los órganos a donar, dispuesto por la familia, en un pabellón quirúrgico. Posterior a esto los órganos donados son trasplantados al receptor que así lo necesite o almacenados (5).

Como se mencionó anteriormente, la baja donación de órganos es un tema de relevancia nacional en Chile. Uno de los autores que ha investigado este tema fue Solar (6). Solar observó que el perfil psicosocial de quienes rechazan la donación de órganos corresponde a personas mayores de 40 años, con un bajo nivel educacional, sin vivencias previas respecto a donación o trasplante de órganos, sin participación en actividades de servicio a la comunidad y que rechazan la donación por considerarla una mutilación y desconocen el concepto de muerte encefálica. Sin embargo, un aspecto fundamental en la donación de órganos y que involucra a todo el personal de salud es la falta de investigaciones acerca de las creencias, valores y emociones asociadas a este tema que poseen las enfermeras y enfermeros. Los enfermeros, responsables del cuidado, son los encargados de la educación a funcionarios, pacientes y familia, al igual que de aspectos administrativos y asistenciales que pueden llevar a hacer efectiva o no una donación de órganos.

La investigación que se presenta a continuación tuvo como objetivo conocer las representaciones sociales de las enfermeras y enfermeros de una unidad de cuidados críticos, en la Región de Coquimbo en Chile, de tal forma de contribuir a una mejor comprensión del fenómeno de la baja donación de órganos en el país. Para efectos de esta investigación se utilizó el concepto de Representaciones Sociales de Denisse Jodelet, quien las designa como una forma de conocimiento específico, el saber del sentido común, cuyos contenidos manifiestan la operación de procesos generativos y funcionales socialmente caracterizados. En el sentido más amplio, designa una forma de pensamiento social (7).

\section{METODOLOGÍA}

Esta investigación corresponde a un estudio de tipo cualitativo, caracterizado por conocer los fenómenos desde la percepción de los enfermeros que se desenvuelven en una Unidad de Paciente Crítico (UPC), es decir, desde sus sentimientos, interpretaciones y subjetividades, lo que lleva a describir la realidad tal cual la experimentan y vivencian dichos protagonistas (8). El enfoque utilizado en este estudio fue la Teoría Fundada, la cual fue creada por los sociólogos Glaser y Strauss en el año 1967. Este método permite la recolección y análisis de los datos cualitativos, para así construir una teoría a partir de la información recopilada de diversas personas quienes son los que viven las experiencias. Para la creación de esta teoría es importante determinar la saturación de los datos, la cual se logra mediante la codificación, muestreo teórico y las comparaciones constantes. Luego de la saturación de los datos se dice que ya no hay información nueva que aportar, por lo que se comienza a relacionar toda la información proveniente de los participantes (9).

Se utilizó como técnica de recolección de datos la entrevista en profundidad y el método de comparación constante. En la entrevista se realizaron preguntas abiertas en relación a los objetivos planteados. Además, se complementó la información recolectada con las notas de campo y memos de los investigadores (10). Las entrevistas fueron transcritas y analizadas sin edición para la confección de los códigos. Una vez obtenidos estos conceptos o códigos, se inició la clasificación o categorización, mediante un proceso inductivo. Luego se procedió a elaborar las familias o supra categorías. Este nivel de análisis corresponde a la codificación abierta (11). Los participantes se seleccionaron de acuerdo a criterios de inclusión fijados previamente. Estos fueron: aceptar voluntariamente participar, firmar el consentimiento informado, tener un año de antigüedad en la unidad de cuidados críticos y haber tenido al menos una experiencia del proceso de procuración de órganos. Como se mencionó anteriormente, el número de participantes estuvo determinado por la saturación teórica de la muestra, la que se alcanzó con cinco enfermeros. Con respecto a los aspectos éticos de esta investigación, se cumplieron con los criterios éticos Ezekiel Emanuel (12). La investigación posee valor dado por su importancia social y científica. Sus resultados podrían facilitar la creación e implementación de programas destinados a brindar herramientas a la población para mejorar su calidad de vida.

Para asegurar la validez científica, se utilizó la Teoría Fundada como perspectiva metodológica. La selección de los participantes fue equitativa, ofreciendo abiertamente la posibilidad de ser parte de la investigación. No hay exposición a riesgo en esta investigación, y los beneficios pueden ser relevantes para el programa de donación de órganos. Los participantes firmaron un consentimiento informado, donde se les asegura el anonimato de la información recogida.

\section{RESULTADOS Y ANÁLISIS}

Una vez finalizadas las entrevistas, se efectuó el análisis. Se identificaron los códigos y categorías y se seleccionó la información que respondía a los objetivos planteados en la investigación de acuerdo a las tres áreas en que se enfocan las representaciones sociales, es decir, cognitivo, afectivo y campo de representación. En la codificación abierta emergieron desde los códigos las siguientes categorías: sentimientos en relación a la donación de órganos; posición personal respecto a la donación; significado de la donación de órganos; características del enfermero en relación a la donación; proceso de donación; 
administración del proceso de donación; ideas para promover la donación; opinión de los familiares de los posibles donantes; conociendo al donante; barreras para la donación y fortalezas institucionales. A continuación se describen las categorías emergentes.

En la categoría "Sentimientos en relación a la donación de órganos", los entrevistados expresan los sentimientos que genera el proceso de donación de órganos. Una vez que se lleva a cabo la donación refieren sentimientos positivos, expresados en los siguientes códigos: satisfacción, felicidad y gratitud. Sin embargo, cuando existe negativa familiar o no se puede llevar a cabo el procuramiento debido a los criterios de exclusión y/o recursos, emergen los códigos: sufrimiento, frustración, impotencia, desesperanza y decepción.

"... saber que tu esfuerzo hizo que otras personas tuvieran vida o que por lo menos que se logró sacar algún órgano del paciente, eso es gratificante, de todo el sabor amargo, queda algo dulce..." (E.1)

“...Yo creo que es súper frustrante cuando uno ve a un paciente que cumple todos los criterios para donar y es casi candidato ideal... y el familiar dice que no, da impotencia..."(E.2)

En relación a la categoría "Significado de la donación de órganos" los enfermeros refirieron que es una forma de prolongar y mejorar la calidad de vida, que para ellos es una forma de trascender a través del tiempo. Los códigos obtenidos en esta categoría son: oportunidad, esperanza, prolongación de la vida, salvar vidas y donación de órganos como necesidad, los cuales se puede reflejar en la siguiente cita:

"...La idea es dar vida y solucionar los problemas de ciertas patologías de los pacientes que están pidiendo una chance...una segunda oportunidad por así decirlo..." (E.5)

La categoría "Posición personal respecto a la donación", se refiere a la postura de los enfermeros respecto a la donación de órganos. Los participantes refieren diversas posiciones en relación al tema, con objeciones de tipo religiosas, falta de conocimientos e información. Los códigos que emergieron después del análisis de las entrevistas fueron: no donante de órganos, donante de órganos, decisión personal y donante como actitud positiva.

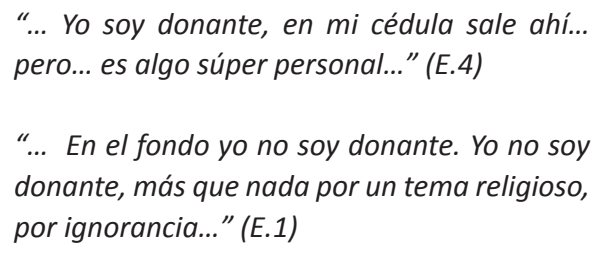

Los enfermeros señalaron que deben poseer ciertas cualidades categorizadas como "Características de los enfermeros con respecto a la donación", las que deben cumplir durante el proceso, ya que es muy importante crear un vínculo con los familiares de los posibles donantes. Dentro de esta categoría se encuentran los siguientes códigos: comunicación eficaz, cercanía con los familiares, empatía, dedicación, apoyo a los familiares, enfermero como facilitador, cualidad humana de Enfermería.

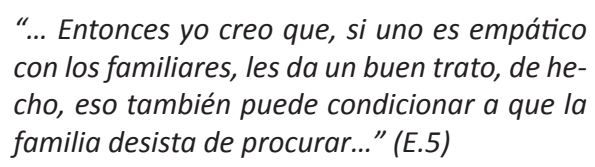
con los familiares, les da un buen trato, de hecho, eso también puede condicionar a que la familia desista de procurar..." (E.5)

La categoría "Conociendo al donante" emerge de la postura de los enfermeros en relación a la forma en que visualizan al donante. Los enfermeros expresan que corresponden a pacientes complejos, que requieren cuidados muy especializados, sin embargo, algunos manifestaron que son órganos vitales que sólo deben mantenerlos funcionando. También se refirieron como "muertos en vida" o "un cadáver". Los códigos emergentes en esta categoría fueron: mantenimiento de órganos, pacientes complejos, pacientes demandantes, trabajo con el muerto, muerto en vida, órganos. Esto es posible observarlo en la siguiente cita:
“...Después ya nosotros tenemos que trabajar $y$ ahí es harto trabajo porque hay que man- tener órganos vivos que no funcionan con un cerebro muerto. Entonces, nosotros sacamos a los familiares de ahí y nos ponemos de lleno a trabajar con el cadáver..." (E.1)

Otra categoría emergente fue "Opiniones de los familiares de los posibles donantes". Los enfermeros expresaron que la decisión, predisposición y estrés familiar pueden favorecer u obstaculizar el proceso de donación de órganos. Los códigos en esta categoría son: estrés familiar, estado de ánimo previo a la muerte, retracción de la decisión familiar, respeto de la última voluntad, condición del donante y negativa familiar, ideas de la familia sobre la donación de órganos.

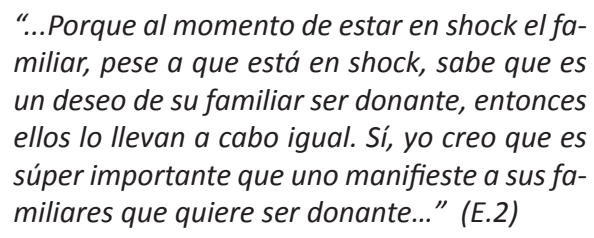

En la categoría "Barreras para la donación de órganos" emergieron factores generales que pueden influir de forma negativa hacia el proceso de donación de órganos. Ellos destacaron principalmente que existe una falta de educación y desinformación en relación al tema por parte de la población en general. También expresaron que al existir poca comunicación con la familia condiciona una negativa por parte de ellos; sin embargo otros entrevistados ven como algo positivo la nula conversación con la familia, ya que se apoyan en la responsabilidad de la enfermera de conversar con la familia sobre el proceso de donación, 
siendo de esta forma un proceso más habitual. Los enfermeros refieren como otro factor importante la forma en que se vive la muerte en Chile y en algunos países de Latinoamérica, en que se comprende como un fenómeno doloroso y trágico, lo que trae como consecuencia un importante apego por parte de los familiares hacia el posible donante. Los códigos obtenidos en esta categoría son: desinformación, religión, criterios de exclusión, falta de educación, mitos de la población, muerte como algo doloroso, apego con el familiar, desconocimiento del receptor, escasa comunicación con los familiares, internalización de la muerte.

\begin{abstract}
"Los familiares dicen que andan robando órganos, que no sé, hay tráfico de órganos, generalmente eso dicen los familiares. No acá, pero no sé, en la casa, en temas de conversación con los amigos..." (E.3)
\end{abstract}

Los profesionales destacan como importante la forma en se produce la muerte, puesto que el ser joven con una muerte rápida hace menos probable que la familia acepte que sea donante. Por otro lado, cuando existen pacientes con varios días de estadía en el hospital y posteriormente a esto se produce la muerte encefálica, los familiares mantienen una postura proclive hacia la donación.

\section{"...Porque se ha estudiado que realmente si uno llega y habla con los familiares, lamen- tablemente se obtiene sólo respuestas nega- tivas, porque el familiar está en shock..." (E.2) \\ "...Si llega un paciente que estaba bien y a la media hora fallece, y además le piden donar órganos, es chocante. Están en la etapa del duelo, en la negación. Ellos dicen ¿cómo se murió y ya me están pidiendo? No sé... yo creo que eso es un factor limitante, para tener una respuesta afirmativa. Pero lamentablemente como esto se trabaja con el tiempo en contra, debe ser así..." (E.3)}

A pesar de lo mencionado anteriormente, otro tema que los enfermeros identificaron claramente son las "Fortalezas institucionales" presentes en el hospital, expresados en los siguientes códigos: presencia de un equipo multidisciplinario, enfermera de procuramiento capacitada, clima laboral de respeto, plaza del donante, insumos, buena organización y la existencia de la unidad de procuramiento, los que corresponden a elementos que pueden potenciar la donación de órganos.

“...Entonces ellos no tenían un espacio físico, no sé... para rezar... para sentarse... Entonces después de eso se creó acá la plaza del donante que es la que está acá abajo, que dice: que es en honor al primer donante que tuvo el hospital de Coquimbo..." (E.1)

En cuanto al "Proceso de donación", fue descrito por los enfermeros en los siguientes códigos: proceso solidario, proceso largo, proceso estructurado, proceso complejo y cuidadoso. Sin embargo, reconocen que el proceso de donación de órganos debe realizarse en el menor tiempo posible, lo cual se contradice con la delicadeza con que se debe tratar el tema con los familiares, presentándose como otra posible barrera a la donación de órganos.

\begin{abstract}
“...A ver es como un proceso... de... solidaridad donde uno, bueno, a nivel profesional siempre da lo mejor de sí..." (E.4)
\end{abstract}

\begin{abstract}
"...Y yo siempre le digo al médico, que es tan poco el tiempo. No sé, yo le daría un poquito más (con énfasis), claro y ella me dice lo mismo que estamos contra el tiempo, entonces creo que eso es un factor importante..." (E.3)
\end{abstract}

"Administración del proceso de donación de órganos" fue otra de las categorías emergentes, en la que los enfermeros expresaron los siguientes códigos: mala infraestructura, falta de camas, falta de profesionales capacitados para la técnica de procuramiento de los órganos, traslado inadecuado de los órganos y la falta de coordinación entre los profesionales que se desempeñan en la unidad de cuidados críticos y la enfermera encargada de procuramiento, lo que en algunos casos podría condicionar al éxito del proceso de donación de órganos.

\section{"...me han tocado casos en que no ha habido helicóptero disponible y se han perdido órga- nos..." (E.4)}

\footnotetext{
“...Falta más la parte médica, que venga un buen equipo y se pueda sacar todo. Muchas veces no se puede sacar ni pulmón ni corazón, porque no están los equipos" (E.3)
}

Finalizando las entrevistas, emergió la categoría "Ideas para promover la donación" en respuesta a la creciente lista de espera de trasplante. A lo cual dieron sugerencias señaladas en los códigos mencionados a continuación: festivales de cine, mayor difusión televisiva, cambio en el marco legal sobre la donación de órganos y creación de una Unidad de Cuidados Intensivos de procuramiento de órganos. Todo esto no se enfocará sólo en el tema de la donación de órganos sino también en el significado e implicancia de la muerte encefálica. Además de conversar con los familiares respecto a la postura personal de ser o no donante.

\footnotetext{
"...Falta mucha difusión para explicar qué es la muerte cerebral, la difusión entre todos los actores involucrados, que las personas conversen con sus familiares porque yo encuentro que no es bueno que la decisión la tenga que tomar el familiar..." (E.2)
} 
Con respecto al cambio en el marco legal, los enfermeros señalan que es imperativo el respeto de la última decisión del donante.

\begin{abstract}
"...Yo creo que quizás se pudiese hacer algo en la ley. Como dejar estipulado, si el familiar dice en vida que sí, se debe procurar que la familia esté al tanto de eso y que lo respete también..." (E.5)
\end{abstract}

\section{“...Es súper importante que haya una reforma respecto a eso, o sea tiene que cambiar el sis- tema, yo creo que la decisión tiene que estar en cada persona... " (E.2)}

\section{DISCUSIÓN}

Los enfermeros refieren una multiplicidad de sentimientos generados durante el proceso de captación y donación de órganos; se encuentra el miedo, por la proyección que se produce ante la idea que les pueda ocurrir algo similar a algún familiar suyo. Además del sufrimiento y dolor que se origina, ellos deben seguir en su rol como profesionales a pesar de la situación compleja que están atravesando los familiares (13). Esto contrasta con los resultados obtenidos en esta investigación, en que, a pesar del desgaste emocional inherente del proceso, se destacan sentimientos de alegría y satisfacción en torno a una respuesta positiva, versus sentimientos de impotencia y frustración ante una respuesta negativa de los familiares.

En cuanto al significado de la donación para los participantes, éstos son similares al estudio de Lima. Ambas investigaciones coinciden en que es un acto de amor y solidaridad, es vivir en otra persona y se convierte en una segunda oportunidad destinada a mejorar la calidad y posibilidad de vida del receptor (13). Los enfermeros refieren que la empatía, el vínculo con los familiares y el actuar de enfermería, constituyen elementos facilitadores de la donación de órganos, llegando a ser elementos claves del perfil profesional en el momento de vincularse con las familias. Esto se condice con las observaciones de Forsberg, cuyo estudio también da cuenta de la importancia de las características antes mencionadas (14). Los participantes enfatizan que debe existir un trato humanizado con los familiares, considerando el difícil momento que sufren y de esta forma actuar como facilitadores, puesto que puede condicionar una decisión positiva. Los participantes que han tenido experiencias previas con donación de órganos son más proclives a promoverla; esto se condice con los resultados obtenidos por Forsberg y Meyer. En ambos estudios se destaca el impacto de la vivencia previa del procuramiento $(14,15)$. El presente estudio se condice con el de Conesa en lo que respecta a la importancia dada por los participantes a la promoción de la donación de órganos (16). En ambos estudios los participantes refieren que el ser donante es una decisión personal, la cual puede ser influida por factores como la religión y el desconocimiento sobre el proceso de donación.
De acuerdo a los resultados obtenidos en la categoría "Conociendo al donante", en la cual se describe la valoración del donante por parte de los enfermeros, como se mencionó antes, éste es definido como una persona muerta en vida o un paciente que requiere de cuidados intensivos debido a la inestabilidad secundaria a la muerte encefálica, correspondiendo a pacientes complejos y demandantes. Sin embargo, es visto como un paciente más, que requiere de los mismos cuidados que un paciente crítico. Resulta llamativo la opinión de algunos participantes que ven al donante como "órganos que deben mantenerse", "muerto en vida" o como un cadáver, lo cual contrasta con los estudios revisados, los cuales destacan al donante como un medio, por lo que no se refieren al donante como un cadáver $(6,14)$.

Un estudio en Brasil expone que los donantes pasan a un segundo plano debido a la falta de recurso humano, material y una adecuada infraestructura para mantenerlo estabilizado, por lo que esto genera un aumento importante de la sobrecarga laboral (6). Esto se contrapone con los hallazgos de nuestra investigación, ya que si bien los enfermeros refieren un aumento de la carga laboral, los cuidados del donante son tan importantes como los de cualquier otro paciente de la unidad. Los enfermeros mencionan que la atención de enfermería inadecuada repercute de forma negativa en la donación de órganos y que en el momento de la entrevista los familiares expresan su rabia contra el sistema de cuidado, dificultando la entrevista. Estos resultados coinciden con Conesa, que investigó la opinión de familiares (16). Entre sus hallazgos se encuentran que la predisposición, el trato con los familiares y los conocimientos previos acerca de la donación de órganos serían determinante al momento de donar. Con respecto a las barreras en la donación de órganos, los estudios coinciden con nuestra investigación en que los factores preponderantes son el temor frente a la mutilación del cuerpo, la falta de información, de comunicación y de educación, la religión y creencias que influyen en que la muerte sea vista culturalmente como algo negativo. Los estudios revisados agregan como barreras importantes la falta de interés y conocimiento en relación al proceso de muerte encefálica de los profesionales, insistencia médica con la familia, incredulidad sobre las capacidades médicas para realizar proceso de donación, además de la falta de apoyo por parte de los profesionales hacia los familiares del donante, situación que no se aprecia en este estudio $(17,18)$.

En relación a la gestión del proceso de donación de órganos, Machuca concuerda con nuestros resultados, coincidiendo en que las principales limitantes son la falta de recurso humano, material e infraestructura. Sin embargo, en el estudio mencionado se identifican también como causa el inadecuado manejo médico de los potenciales donantes (19). En cuanto a posibles medidas para apoyar la donación, las investigaciones recogen ideas destinadas a responder la creciente demanda de órganos, de las cuales destacan la educación sobre muerte encefálica tanto al personal de salud como a la población general, dar a conocer el proceso mediante el cual se lleva a cabo la donación de órganos, además de dialogar con los familiares sobre el proceso, facilitando información y promoviendo el desarrollo de mecanismos para enfrentar bien la pérdida (6). 


\section{CONCLUSIONES}

La realización de esta investigación permite tener una visión más amplia de la problemática de la baja donación de órganos en Chile, abarcando el problema desde una perspectiva cualitativa desde la mirada de Enfermería. Los enfermeros comprenden la donación de órganos como un proceso complejo y estructurado, que genera un importante estrés y sobrecarga laboral y emocional; sin embargo, para ellos los beneficios de este proceso justifican el difícil momento por el que cursan. Aunque refieren que el proceso de procuramiento de órganos está bien implementado, de acuerdo al protocolo de la Unidad de Procuramiento de Órganos, existen factores que actúan como limitantes tales como la familia, debido a que ésta tiene la última decisión respecto a la donación y el momento álgido en que se encuentran. Por otro lado el tiempo es otra limitante a considerar, ya que el proceso debe llevarse a cabo en el menor tiempo posible para asegurar su éxito. A su vez mencionan como otro factor determinante la falta de profesionales capacitados para ejecutar el relevamiento al igual que la falta de camas en Unidades de Cuidados Intensivos, lo que muchas veces determina la pérdida de un potencial donante. De acuerdo a los profesionales de enfermería en relación a las causas de baja donación de órganos, es la falta de empoderamiento de la población general en relación al proceso de donación y en específico lo que significa e implica la muerte encefálica. Esto es evidenciado por la dificultad de los familiares de internalizar que el potencial donante se encuentra sostenido por máquinas que dan soporte vital con el objetivo de asegurar la viabilidad de los órganos para su posterior trasplante. De aquí se desprende que es fundamental generar un cambio a nivel cultural y educativo sobre lo que significa la muerte encefálica, convirtiéndose en el primer paso para cambiar la disposición respecto a ser o no donante. De forma complementaria se convierte en una necesidad realizar un cambio a nivel del marco legal, con el objetivo de resguardar la última voluntad del donante. Es necesario relevar la importancia de la donación de órganos, ya que es la única solución a ciertas patologías, lo que permite mejorar y prolongar la esperanza de vida de las personas. Se sugiere continuar con los estudios cualitativos y cuantitativos que incluyan a todos los actores involucrados, es decir, usuarios de todas las edades y condición socio cultural, personal y gerencia de salud, elaborando en conjunto políticas públicas que fomenten la donación de órganos.

\section{REFERENCIAS BIBLIOGRÁFICAS}

1. Consejo Internacional de Enfermería (C.I.E.). [Internet] [citado Set 2015]. Disponible en: http://www.icn.ch/es/whowe-are/icn-definition-of-nursing/

2. Carral Novo, J. Aspectos Históricos y Bioéticos sobre los Trasplantes de Órganos. Rev Cub Med Int Emerg [Internet] 2003. [citado Abr 2016]; 2 (80-83). Disponible en: http:// www.bvs.sld.cu/revistas/mie/vol2_1_03/mie11103.pdf

3. Ministerio de Salud. Donación y trasplantes de órganos y tejidos [Internet] Chile: Ministerio de Salud. [Acceso 14 de enero de 2015]. Disponible en: http://web.minsal.cl/preguntas_trasplantes

4. Rojas, J. Orientaciones técnicas: Proceso de Procuramiento de Órganos y Tejidos para trasplante (Ministerio de Salud).
[Internet] 2012. [citado Nov 2016]; (1): 1-17. Disponible en:http://web.minsal.cl/sites/default/files/files/7_\%20Donaci\%C3\%B3n\%20de\%20\%C3\%93rganos\%20Sangre\%20 y\%20Tejidos\%202015\%20v2.docx

5. Pefaur J., Rosati M., Zehnder C., Toro J., Mireya A., Elgueta S., et al. Trasplante renal. Sociedad Chilena de Trasplante $2009 ; 1(2): 103$.

6. Solar, S. Ovalle, A. Tres Factores que Influyen en la Actitud de las Personas Ante la Donación de Órganos. Rev. Chilena de Cirugía. 60 (3): 262-267

7. Jodelet, D. La representación social: fenómenos, conceptos y teoría En: Moscovici, S, editor. Psicología Social 2. Barcelona: Paidós; 1984. $402-414$

8. Vanegas, V. La investigación cualitativa: un importante abordaje del conocimiento para enfermería. Revista Colombiana de Enfermería. 2007. 6 (6): 128-142

9. Campo M, Labarca, C. La teoría fundamentada en el Estudio empírico de las Representaciones Sociales: Un caso Sobre el rol orientador del Docente. Opción 2009, 25 (60): 43-48

10. Cuñat, R. "Aplicación de la Teoría Fundamentada (Grounded Theory) al Estudio del Proceso de Creación de Empresas" XX Congreso anual de AEDEM. [Internet]. 2007 [citado May 2016] Disponible en: http://dialnet.unirioja.es/servlet/articulo?codigo $=2499458$

11. Charmaz K. Constructing Grounded Theory. 2da Ed. Ed. London: United: Sage; 2014

12. González, M. Aspectos éticos de la investigación cualitativa. Revista interamericana de educación. [Internet] 2002. [citado Jul 2016]; 29: 85-103. Disponible en: http://www.rieoei. org/rie29a04.htm

13. Lima, A. Sufrimiento y contradicción: el significado de la muerte y del morir para los que trabajan en el proceso de enfermeros donación de órganos para trasplante. Enfermería Global [Internet]. 2009 [citado Sep sept 2016]; 5: 1-16 Disponible en: http://scielo.isciii.es/pdf/eg/n15/clinica1. pdf

14. Forsberg, A. Attitudes towards organ donor advocacy among Swedish intensive care nurses. British Association of Critical Care Nurses. 2015; 20 (3): 126-133.

15. Meyer, K. Bjørk I.I. \& Eide H. Intensive care nurses' perceptions of their professional competence in the organ donor process. Journal of Advanced Nursing .2015; 68 (1), 104115.

16. Conesa, C., Ríos, A. Estudio multivariante de los factores psicosociales que influyen en la actitud poblacional hacia la donación de órganos. Revista de Nefrología. [Internet] 2005; [citado Abr 2016] 25 (6): 684-697 Disponible en: http://www.revistanefrologia.com/es-publicacion-nefrologia-articulo-estudio-multivariante-de-los-factores-psicosociales-que-influyen-en-la-X0211699505019359

17. Bustamante M., Villarroel P. Motivación a la Donación de Órganos en Chile. Panorama Socioeconómico. 2008: 26 (36): 86-97.

18. Avilés L., Rivera M., Catoni M. Donar, un cambio de vida: comprender la experiencia de familiares que aceptaron la donación de órganos. Rev Med Chile. 2014: 142(6): 702-706

19. Machuca, F. Evaluación y mejora del mantenimiento del potencial donante en la unidad de cuidados intensivos adultos del Hospital San Pablo de Coquimbo, Chile Cuidados de Enfermería y Educación en Salud (Chile). 2014: 1(2): 16-42. 